\title{
GROWTH OF MATRIX CRACKS DURING INTERMEDIATE TEMPERATURE STRESS RUPTURE OF A SiC/SiC COMPOSITE IN AIR
}

Gregory N. Morscher

Ohio Aerospace Institute

NASA Glenn Research Center, MS 106-5

Cleveland, $\mathrm{OH} 44135$

\begin{abstract}
The crack density of woven Hi-Nicalon ${ }^{\mathrm{TM}}$ (Nippon Carbon, Japan) fiber, $\mathrm{BN}$ interphase, melt-infiltrated $\mathrm{SiC}$ matrix composites was determined for specimens subjected to tensile stress rupture at $815^{\circ} \mathrm{C}$. A significant amount of matrix cracking occurs due to the growth of fiber-bridged microcracks even at stresses below the run-out condition. This increased cracking corresponded to time dependent strain accumulation and acoustic emission activity during the constant load test. However, the portion of the rupture specimens subjected to cooler temperatures $(<600 \mathrm{C})$ than the hot section had significantly lower crack densities compared to the hotter regions. From the acoustic emission and time dependent strain data it can be inferred that most of the matrix crack growth occurred within the first few hours of the tensile rupture experiment. The crack growth was attributed to an interphase recession mechanism that is enhanced by the presence of a thin carbon layer between the fiber and the matrix as a result of the composite fabrication process. One important consequence of matrix crack growth at the lower stresses is poor retained strength at room temperature for specimens that did not fail.

\section{INTRODUCTION}

Fiber-bridged matrix cracking is of course desirable for good toughness properties in ceramic matrix composites. However, for non-oxide ceramic matrix composites during stressed-oxidation conditions, matrix cracks are a path for the environment to access the interior of the composite. This results in embrittlement of the load-bearing fibers due to reactions between the oxidizing environment and non-oxide fiber, interphase, and matrix. Therefore, an understanding of the nature of matrix crack formation and progression for stressed-oxidation conditions is important for understanding how these types of composites eventually fail at intermediate temperatures.
\end{abstract}


There are two aspects to matrix crack formation and growth that need to be considered. First, matrix cracks form and propagate due to the applied stress. Matrix crack progression has been determined for CVI SiC matrix composites by Guillaumat and Lamon [1,2] and Pulvinage et al [3] as follows: first cracks form at the sharp regions at large pores which are prevalent in the CVI matrix, then cracks form in $90^{\circ}$ bundles. As stress is increased, these microcracks grow into the load-bearing, $0^{\circ}$ bundles. As stress is further increased, new cracks form in the $0^{\circ}$ bundles. The "knee" in the stress-strain curve is associated with the prevalence of $0^{\circ}$ cracks that coalesce up to form through-thickness cracks. The same matrix crack progression occurs for melt-infiltrated (MI) matrix composites except that the first cracks occur at the surface or the $90^{\circ}$ bundles because there are no large matrix pores $[4,5]$. Therefore, for MI composites, the first cracking stress occurs at a higher stress-strain condition than for CVI composites.

Two aspects of intermediate temperature rupture have been related to the initial matrix cracking state. First, the run-out stress condition (stress rupture) corresponds to the onset-stress for $0^{\circ}$ cracking for $\mathrm{BN}$ interphase composites [5-7] whereas the run-out stress condition for $\mathrm{C}$ interphase composite corresponds to the first cracking stress (about half the stress of the $0^{\circ}$ crack onset stress) as was shown earlier by Lipetzky et al [8] and Steyer and Zok [9]. Second, for BN interphase, MI matrix composites[7], the slope of the rupture stress versus time curve is steeper at higher stresses than at lower stresses (see Figure 1). The transition in slope corresponds to the knee in the stress-strain curve, i.e. throughthickness cracking.

The second consideration is that matrix cracks can also propagate over time under constant load at intermediate temperatures in oxidizing atmospheres. Henager and Jones [10] showed that creep of the bridging fibers and/or recession of the interphase can result in crack opening thereby increasing the stress intensity on the crack tip and matrix crack growth into the composite. If the stress on the fibers is large enough in the crack wake, fiber breakage can occur resulting in unbridged crack growth. Evans, Zok and coworkers demonstrated [11] and modeled [12] a case where oxidation of the fiber matrix interface in a microcrack results in the strong bonding of fibers to one another or the matrix and the propagation of non-bridged matrix cracks. The temperature and oxygenconcentration regime at which these mechanisms control failure has been constructed as a failure mechanism map by Lewinsohn et al. [13]. For HiNicalon ${ }^{\mathrm{TM}}$ reinforced $\mathrm{BN}$ interphase, MI SiC matrix composites [7], at lower stresses it appears that both bridged and unbridged matrix crack growth occurs and eventually leads to composite failure. The nature of matrix crack growth for this system will be further explored in this work.

\section{EXPERIMENTAL}


Specimens that

had undergone tensile stress-rupture loading at $815^{\circ} \mathrm{C}$ in reference 7 were polished longitudinally in order to measure the crack spacing in the $0^{\circ}$ bundles. The specimens consisted of woven $\mathrm{Hi}-\mathrm{Nicalon}{ }^{\mathrm{TM}}$ fibers, $\mathrm{BN}$ interphases, and a MI matrix. The MI matrix consists of a CVI SiC layer next to the interphase and a combination of $\mathrm{SiC}$ particulate in free silicon making up the rest of the matrix volume that has little porosity. See reference

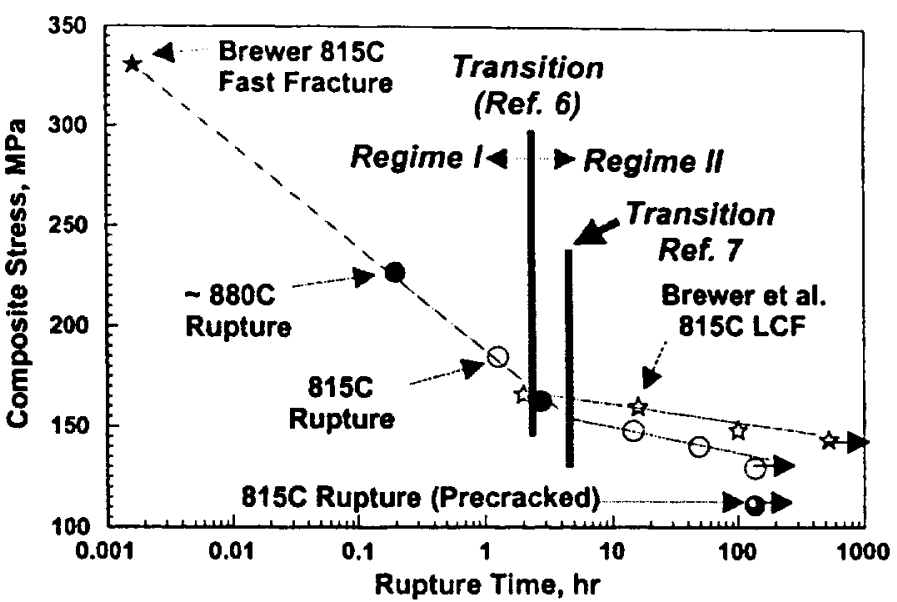

Figure 1: Stress versus time data for two different $\mathrm{Hi}-$ Nicalon $^{\text {TM }}$, BN interphase, MI SiC matrix composites. The data from Brewer et al. [6] were acquired under a very low cycle fatigue condition ( 2 hour hold followed by a quck unloading and reloading to the same hold load, see reference 12). The arrows indicate the specimens did not fail.

14 for processing

details. Some of the specimens were plasma etched in order to bring out the cracks in the CVI $\mathrm{SiC}$ matrix surrounding the loadbearing fibers. Matrix cracks were counted over $10 \mathrm{~mm}$ lengths in order to determine the crack density over that measured length. The crack densities for an outer load-bearing bundle and for an interior load-bearing bundle were measured. The average crack density of the inner and outer bundles were then compared to the temperature profile of the furnace that the tensile specimen was exposed to during the rupture test.

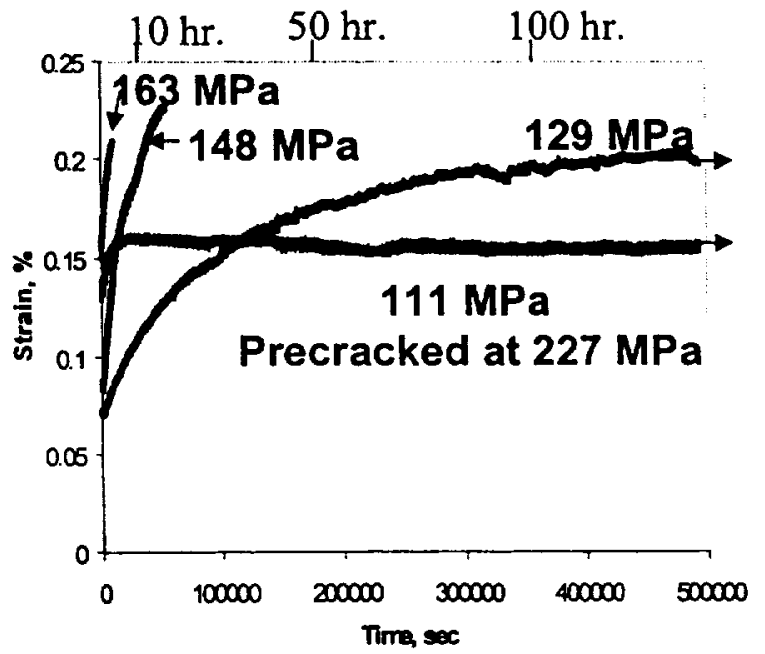

Figure 2: Strain versus time for some of the specimens subjected to stress-rupture at $815^{\circ} \mathrm{C}$ from reference 7 . 


\section{RESULTS}

Figures 1 and 2 show the stress and strain versus time stress-rupture data, references 6 and 7 , for specimens tested at $815^{\circ} \mathrm{C}$ in air, respectively. The "transition" in Figure 1 designates the change from a faster rupture rate to a slower rupture rate which also corresponds to the "knee" in the stress-strain curve for both composite panels. The strains increase at a decelerating rate with time similar to a tensile creep curve. The only exception is for the specimen that was precracked at $227 \mathrm{MPa}$ and then subjected to $110 \mathrm{MPa}$ stress-rupture. This specimen did not fail and showed little increase in strain with time. The increase in strain with time must be due to an increase in cracking and/or an increase in crack opening.

Acoustic emission data from the $148 \mathrm{MPa}$, 14.8 hour rupture test is shown in Figures 3 and 4. The location of the two highest decades of energy events is shown in Figure 3 as well as the temperature profile of the furnace used in the rupture test. Most of the acoustic emission events occurred in the first few hours of the test; however, a few loud events occurred in several locations at longer times; the ultimate failure location corresponds to the area where most of these later $\mathrm{AE}$ events occurred. It has been shown that AE energy corresponds directly with matrix cracking for both room temperature [15] and elevated temperature [16] tests. Therefore, most of the

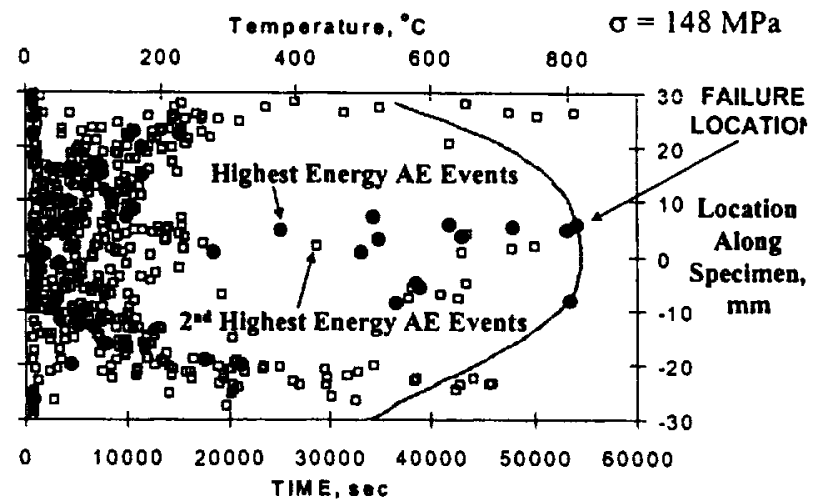

Figure 3: Location of loudest (circles $=$ highest energy events; squares $=2^{\text {nd }}$ highest decade of $A E$ energy events) $A E$ events and temperature profile of furnace for specimen tested at $148 \mathrm{MPa}$.

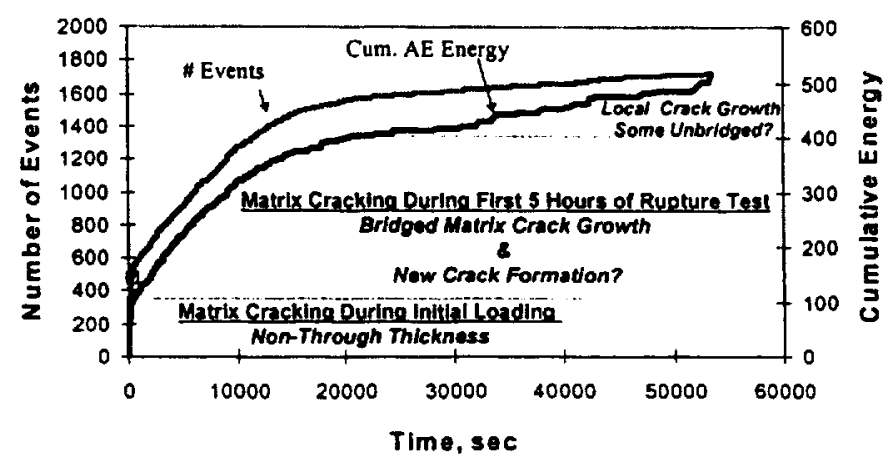

Figure 4: Number of $A E$ events and cumulative $A E$ energy for events occurring in the $15 \mathrm{~mm}$ hot zone of the furnace. 
AE activity in the first few hours of the experiment must correspond to matrix crack growth and/or formation. The amount of AE activity in the first few hours of the test was even a larger amount than was recorded during initial loading (Figure 4) for this stress condition. It should be noted that for stresses above the "knee" in the stress-strain curve, more AE activity occurs during loading than during the constant load part of the stress-rupture test [7].

The measured matrix crack density and furnace temperature profile versus location along the test specimen are shown in Figure 5. The crack saturation condition for room temperature specimens tested to failure for this panel was $2.4 \mathrm{~mm}^{-1}$. It is evident that a significantly greater amount of matrix cracking occurred in the hot sections of the furnace, greater than $\sim 600^{\circ} \mathrm{C}$, than at lower temperatures. For the higher stress specimen (185 MPa), the crack density reached the

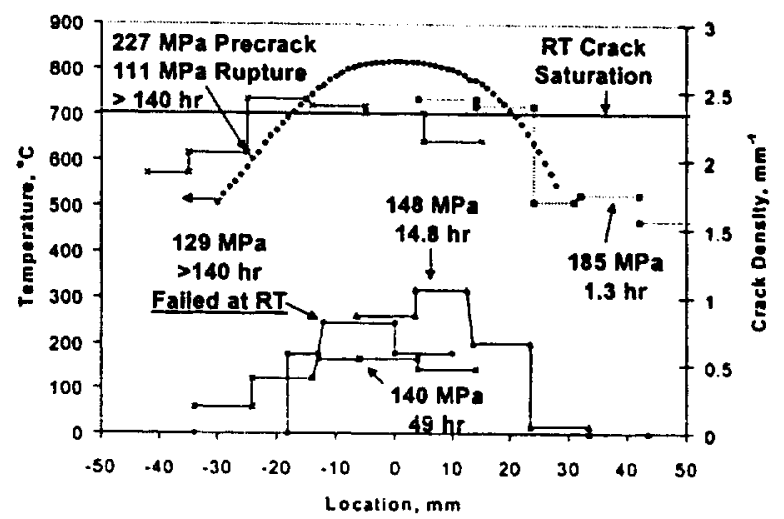

Figure 5: Matrix crack density and temperature profile along the length of the rupture specimens tested at $815^{\circ} \mathrm{C}$ in reference 7.

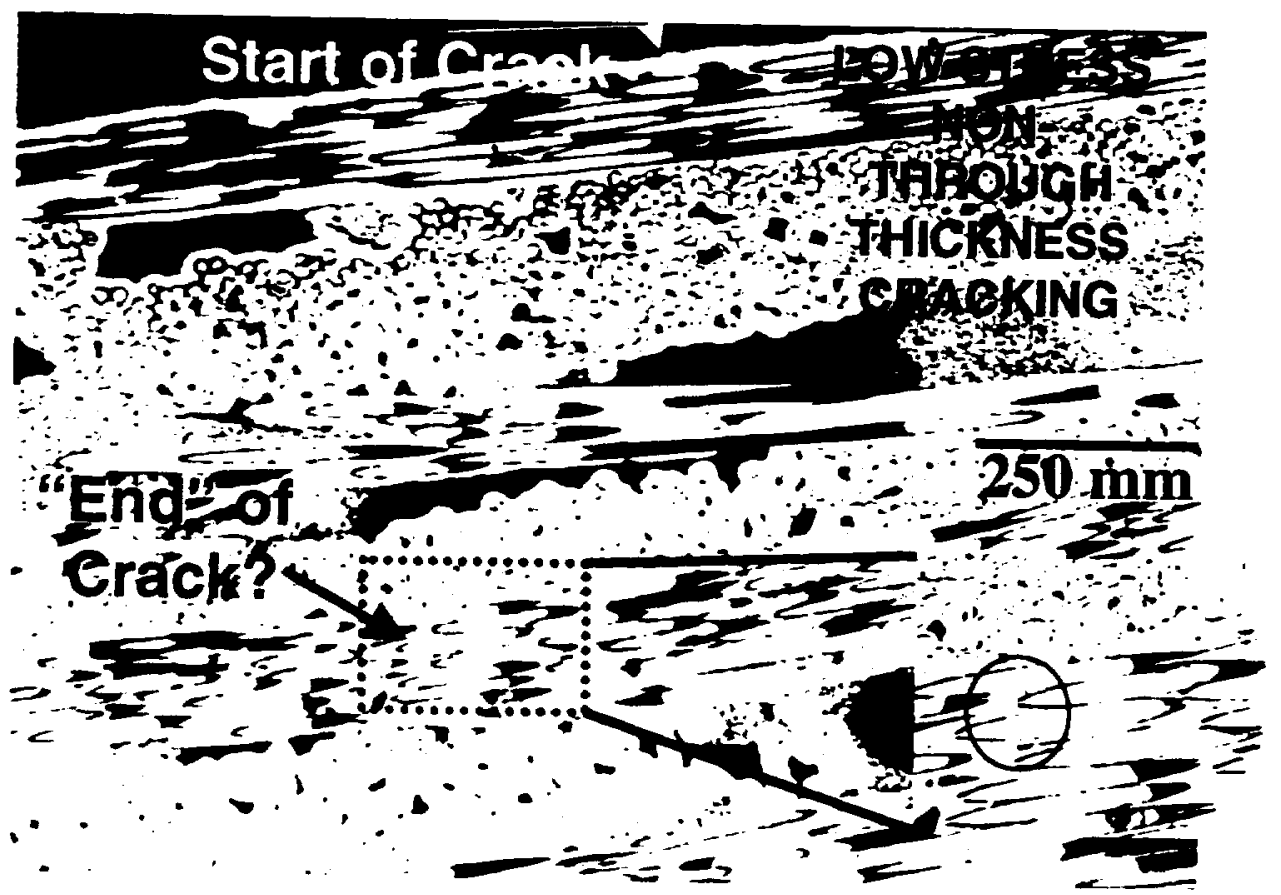

Figure 6: Optical micrograph of specimen tested at $148 \mathrm{MPa}$ showing an example of a non-through thickness crack. 
saturation crack density in the hot region. For the lower stresses, the crack density in the hot region was 0.5 to $1.0 \mathrm{~mm}^{-1}$ and less than $0.2 \mathrm{~mm}^{-1}$ in the cold region.

It is important to note that for the specimens tested at lower stresses, the crack density in the outer plies is greater than in the interior plies. In fact in the cold regions very few if any cracks were observed in the interior bundles.

Evidently, cracks formed at surface defects and propagated inward with time (Figure 6). The specimens tested at higher stresses (above the transition stress in Figure 1) had some through-thickness cracks; however, growth of some microcracks occurred for stress conditions corresponding to initial crack densities below the saturation crack density (Figure 5). It should also be noted that very few fiber failures were observed over the entire polished longitudinal section except very near the failure crack (Figure $7 \mathrm{~b}$ ). The fiber fragmentation near the final failure crack was observed for all of the specimens that failed during rupture in reference 7 ; however, it was most pronounced for the two lower stresses (140 and $148 \mathrm{MPa}$ ).

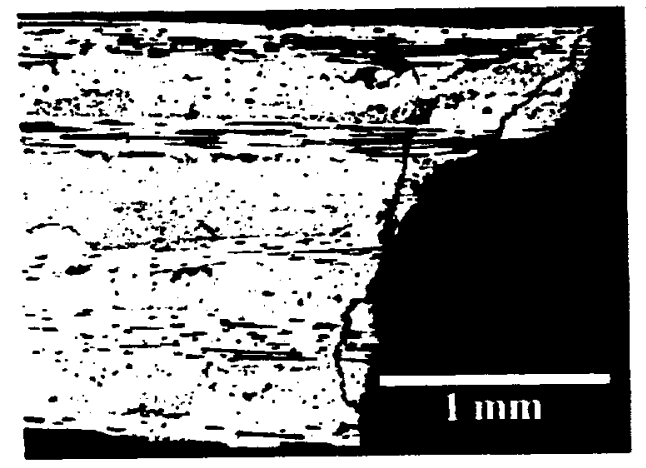

(a)

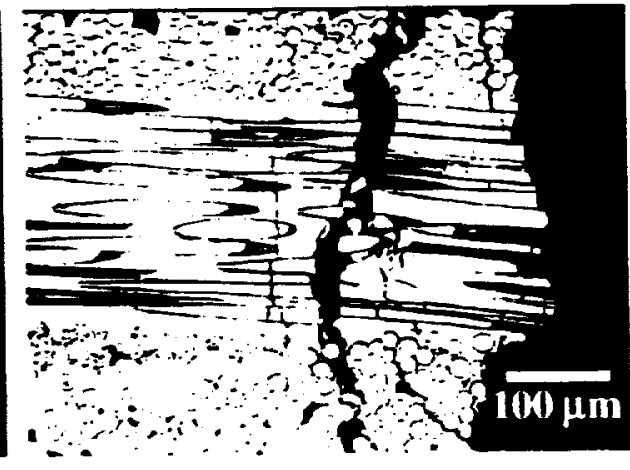

(b)

Figure 7: Polished longitudinal section of the fracture surface for specimen that failed at $148 \mathrm{MPa}$ after 14.8 hours.

\section{DISCUSSION}

Since most of the AE activity occurred during the first few hours of the test after reaching the rupture stress, it can be assumed that most of this $\mathrm{AE}$ activity corresponded to bridged matrix cracking (Figure 4). The onset stress for $0^{\circ}$ cracking was determined to be $\sim 130 \mathrm{MPa}[5]$ for the composite tested in reference 7 and the transition stress was determined to be $\sim 155 \mathrm{MPa}$ (Figure 1). However, for room temperature tensile tests, half of the total AE activity occurred prior to $155 \mathrm{MPa}$. This was attributed to the initial formation of tunnel cracks and 
bridged non-through thickness microcracks [15] and implies that there are a significant number of microcrack sites available for crack growth. This inference appears to be confirmed from the results of this study.

However, after longer times, the AE events are fewer and more localized and may be associated with some unbridged matrix cracking which would increase the load on the remaining fibers in the crack resulting in further unbridged crack growth until composite failure.

Since little fiber breakage is found outside of the failure matrix crack, intermediate temperature embrittlement for this system appears to be controlled by two of the mechanisms described above: interphase recession and fiber embrittlement (i.e. strong bonding). Fiber creep would be negligible for $\mathrm{Hi}$ Nicalon fibers at $815^{\circ} \mathrm{C}$ [17]. It was observed in reference 7 , for composite fracture surfaces of specimens that failed after one hour, that preferential oxidation occurred in between two fibers spaced closely together $(\sim 50 \mathrm{~nm})$ and around the fiber circumference, i.e. in between the fiber and the BN. This was attributed to the presence of a carbon layer that forms between the fiber and the interphase due to MI processing [18]. The early departure of carbon would lower the interfacial shear stress and possibly decouple a fiber near the matrix crack. Since most of the crack growth occurred within the first few hours of the experiment, the recession of the carbon layer is presumed to be the major contributor to matrix crack growth. BN recession would also occur but is much slower for these conditions, no more than a few microns in the first few hours at $815^{\circ} \mathrm{C}[19]$.

The localization of damage leading up to ultimate failure is probably associated with the failure of embrittled fibers and growth of unbridged matrix cracks.

One of the consequences of matrix crack growth is the access of the environment to the interior of the composite and fiber embrittlement. As a result, even if the composite does not fail during a rupture test, the retained strength of a rupture specimen at room temperature is severely degraded. For example, the two specimens that survived 140 hours at 110 and $129 \mathrm{MPa}$ applied rupture stresses both failed at stresses below the applied rupture stress at room temperature [7]. Composites that do not have the carbon layer between the fiber and BN, e.g. Sylramic $($ fiber reinforced composites, do not have as much crack growth or fiber embrittlement and exhibit better retained strength properties [19].

\section{CONCLUSIONS}

Crack growth, during intermediate temperature stress rupture of $\mathrm{Hi}$ Nicalon ${ }^{\mathrm{TM}} / \mathrm{BN} / \mathrm{MI}-\mathrm{SiC}$ composites is substantial. The presence of microcracks that reach the surface of the composite allows the environment to react with the interphase and cause recession of the interphase. A thin carbon layer in these 
composites between the fiber and the BN exacerbates this process. One detrimental consequence of this phenomenon is poor retained strength of these composites at room temperature due to the embrittlement of fibers in the matrix cracks which had grown during service.

\section{REFERENCES}

1. Guillaumat, L. and Lamon, J., "Multi-fissuration de Composites SiC/SiC," in Revue des Composites et des Materiaux Avances, vol. 3, 1993, pp. 159-171.

2. Guillaumat, L. and Lamon, J., "Probabilistic-Statistical Simulation of the Non-Linear Mechanical Behavior of a Woven SiC/SiC Composite," Composites Science and Technology, Vol. 56, 1996, pp. 803-808.

3. Pluvinage, P., Parvizi-Majidi, A., and Chou, T.W., "Damage Characterization of Two-Dimensional woven and Three-Dimensional Braided SiC-SiC Composites," Journal of Materials Science, Vol. 31, 1996, 232-241.

4. Morscher, G.N. and Gyekenesi, J.Z., "Room Temperature Tensile Behavior and Damage Accumulation of Hi-Nicalon Reinforced SiC Matrix Composites," Ceramic Engineering Science Proceedings, Vol. 19, No. 3, 1998, pp. 241-249.

5. G.N. Morscher, J.Z. Gyekenesi, and R.T. Bhatt, "Damage Accumulation in Woven $\mathrm{SiC} / \mathrm{SiC}$ Composites,"," submitted to Environmental, Mechanical, and Thermal Properties and Performance of Continuous Fiber Ceramic Composite (CFCC) Materials and Components, ASTM STP 1392

6. D. Brewer, A. Calomino, and M. Verilli, Unpublished data from the Enabling Propusion Materials Program at NASA Glenn Research Center.

7. Morscher, G.N., Hurst, J., and Brewer, D., "Intermediate Temperature Stress Rupture of a Woven Hi-Nicalon, BN-Interphase, SiC Matrix Composite in Air," Journal of the American Ceramic Society in print.

8. Lipetzky, P., Stoloff, N.S., and Dvorak, G.J., "Atmospheric Effects on HighTemperature Lifetime of Ceramic Composites," Ceramic Engineering Science Proceedings, Vol. 18, No. 4, 1997, pp. 355-362.

9. Steyer, T.E. and Zok, F.W., "Stress Rupture of an Enhanced Nicalon ${ }^{\mathrm{TM}} / \mathrm{SiC}$ Composite at Intermediate Temperatures," Journal of the American Ceramic Society, Vol. 81, No. 8, 1998, pp. 2140-46

10. C.H. Henager Jr. and R.H. Jones, "Subcritical Crack Growth in CVI Silicon Carbide Reinforced with Nicalon Fibers: Experiment and Model," J. Am. Ceram. Soc., 77 [9] $2381-94$ (1994)

11. Heredia, F.E., McNulty, J.C., Zok, F.W., and Evans, A.G., "Oxidation Embrittlement Probe for Ceramic-Matrix Composites," Journal of the American Ceramic Society., Vol. 78, No. 8, 1995, pp. 2097-2100.

12. A.G. Evans, F.W. Zok, R.M. McMeeking, and Z.Z. Du, "Models of HighTemperature, Environmentally Assisted Embrittlement in Ceramic-Matrix Composites," J. Am. Ceram. Soc., 79 [9] 2345-52 (1996)

13. C.A. Lewinsohn, C.H. Henager, Jr. and R.H. Jones, "Environmentally-Induced Failure Mechanism Mapping for Continuous-Fiber, Ceramic Composites," Advances 
in Ceramic Matrix Composites IV. Ceramic Transactions Vol. 96, e.d. J.P. Singh and N.P. Bansal, pp. 351-360, 1999

14. D. Brewer, "HSR/EPM Combustor Materials Development Program," Mater. Sci. Eng. A, A261, 184-291 (1999)

15. Morscher, G.N., "Use of Modal Acoustic Emission for Source Identification in Woven SiC/SiC Composites," Review of Progress in Quantitative Nondestructive Evaluation, Vol. 19, , D.O. Thompson and D.E. Chimenti, Eds., Kluwer Academic/Plenum Publishers, 2000 in print.

16. Morscher, G.N., "Modal Acoustic Emission of Damage Accumulation in Woven $\mathrm{SiC} / \mathrm{SiC}$ at Elevated Temperatures," in Review of Progress in Quantitative Nondestructive Evaluation, Vol. 18A, D.O. Thompson and D.E. Chimenti, Eds., Kluwer Academic/Plenum Publishers, NY, 1999, pp. 419-426.

17. J.A. DiCarlo, H.M. Yun, and J.C. Goldsby, "Creep and Rupture Behavior of Advanced SiC Fibers," Proc. ICCM-10, Whistler B.D., Canada, Vol. VI, p. 315 (1995)

18. L. U. J. T. Ogbuji, "Identification of a Carbon Sublayer in a Hi-Nicalon/BN/SiC Composite," J. Mater. Sci. Letters, vol. 18, pp. 1825-1827 (1999)

19. M.K. Brun and K.L. Luthra, "Ends-on Oxidation of BN Fiber Coatings in SiC-Si/SiC Composites," presented at Annual American Ceramic Society Conference, 1997

20. G.N. Morscher, unpublished research. 
